\title{
Physical activity and sleep on the risk of overweight among Grade 5 students in Gampaha Medical Officer of Health area, Sri Lanka
}

\author{
Upuli Perera $^{1 *}$, Chrishantha Abeysena ${ }^{2}$ \\ ${ }^{1}$ Postgraduate Institute of Medicine, University of Colombo, Sri Lanka; ${ }^{2}$ Department of Public Health, \\ Faculty of Medicine, University of Kelaniya, Sri Lanka \\ *Correspondence: upuliaruna@yahoo.com
}

DOI: http://doi.org/10.4038/jccpsl.v23i1.8090

Received on: 30 October 2016

Accepted on: 24 January 2017

\begin{abstract}
Background: Overweight in childhood is an emerging health problem in developing countries. The increasing trend in overweight is associated with three important factors; dietary habits, physical activity and socio-economic changes.

Objective: To determine the risk factors for overweight among Grade 5 students in schools of Gampaha Medical Officer of Health area.

Methods: A case control study was carried out. Cases were defined as Grade 5 students who were overweight, which was identified based on the age and sex specific body mass index (BMI) centile charts recommended by the International Obesity Task Force. Controls were those who were not overweight selected from the same class of cases. A pre-tested self-administered questionnaire was administered to the parent or guardian of the children to assess the physical activities, dietary pattern and socio-demographic characteristics of children. Multiple logistic regression analysis was applied. Risk factors for overweight were assessed using adjusted odds ratio (aOR) with 95\% confidence interval (CI).
\end{abstract}

Results: Less physical activity during free times at home (OR=1.86; 95\% CI=1.01, 3.42), less physical activity during weekends $(\mathrm{OR}=2.06$; 95\% $\mathrm{CI}=1.18$, 3.61), less overall physical activity $(\mathrm{OR}=1.77 ; 95 \% \mathrm{CI}=1.08,2.9)$ and sleeping more than 8 hours per day $(\mathrm{OR}=0.46 ; 95 \% \mathrm{CI}=0.29,0.74)$ showed statistically significant associations with overweight in bivariate analysis. Of them, after adjusting for confounders, engaging in less physical activities during the weekend was a risk factor $(\mathrm{aOR}=2.17 ; 95 \% \mathrm{CI}=1.22,3.86)$ for overweight. Sleeping more than 8 hours per day was a protective factor $(\mathrm{aOR}=0.46$; 95\% CI=0.29, 0.74) for overweight. Other characteristics of physical activities, socio-demographic factors, high-fibre diet and fatty food did not show any significant association with overweight.

Conclusions: Less physical activity especially during weekends showed a two-fold risk for overweight while sleeping more than 8 hours per day showed a similar protective effect for overweight among Grade 5 school children.

Key words: overweight, physical activity, risk, schooling, sleeping 


\section{Introduction}

Childhood overweight and obesity are becoming an increasingly important public health problem both in developed and developing countries, contributing towards a double burden along with the long-standing issue of under nutrition.

Overweight is the consequence of an energy imbalance in the body. Obesity develops when energy intake exceeds the energy expenditure over a considerable period of time. There are many complex and diverse factors that give rise to this positive energy balance. In relation to one's lifestyle, increased intake of fat and energy density of the diet, and reduction in the level of physical activity are found to be the major contributory factors for overweight (1).

Childhood overweight and obesity are associated with many adverse effects and health risks including physical and psychosocial problems in a child. Further, such children are at increased risk of developing cardiovascular diseases, certain cancers, hyper-insulinaemia, impaired glucose tolerance, increased blood lipids and raised blood pressure during adolescence and adult life (2).

Several studies have identified some important risk factors for childhood overweight and obesity. Sociodemographic factors such as age, sex, residence, family income, and parental education and employment status have shown both positive and negative associations with overweight in different studies (3-7). With regards to diet, high intake of energy dense and micronutrient poor food and beverages (e.g. fast food, processed snacks, sugar-sweetened drinks) consumed by children is shown to be associated with overweight (8-9). In addition, lack of sports and recreational activities, television viewing and increased use of computer have shown positive relationships in overweight children (5-6, 8, 10). Also in a few studies, poor sleep has been identified as a risk factor for childhood overweight (9, 11-13).

In the recent past, various changes in the social, economic and physical environment have taken place in Sri Lanka. With such changes, the lifestyle of adults as well as of children has undergone drastic changes. For example, the eating habits of children have been heavily influenced by lack of time of mothers in preparing meals at home, the increased availability of fast food outlets, and easy access to cheap yet unhealthy food items. The amount of physical activity has been influenced by the competition among children for higher grades at school, compelling them to attend extra classes using the time otherwise spent on physical activities. Television viewing, playing computer games and the increased use of private transport have contributed towards a sedentary lifestyle among children, all of which seem to have worsened the prevalence of overweight in children in Sri Lanka.

Treatment of overweight especially in children is costly and achieving targets is difficult. Treatment procedures could easily frustrate children, parents as well as physicians. Therefore, prevention of overweight and obesity plays a bigger role, which in turn requires a broad understanding of the risk factors specific for childhood overweight. Such risk factor identification provides direction in planning future interventions for prevention. In the Sri Lankan context, only a few associated factors for childhood overweight have been identified. These too had been based on cross-sectional studies, with limited value in quantifying the magnitude of the risks involved $(3,8)$. Therefore, the present study was conducted using an analytical approach to determine the risk factors for overweight among Grade 5 school children in the Gampaha Medical Officer of Health (MOH) area.

\section{Methods}

A case control study was conducted among children in Gampaha $\mathrm{MOH}$ area. The study population included children studying in Grade 5 classes in government schools belonging to different types of $1 \mathrm{AB}, 1 \mathrm{C}, 2$ and 3 , semi-government schools and international schools. The estimated sample size was 318 with 106 cases and 212 controls, based on an estimated exposure rate of $30 \%$, an estimated odds ratio (OR) of 2 and 1:2 desired case to control ratio (9).

A case was defined as a student studying in Grade 5 in a school of Gampaha MOH area with a body mass index (BMI) value above the cut-off points for overweight i.e. 85th centile based on the age and sex specific BMI centile charts recommended by the International Obesity Task Force (14). A control was defined as a student studying in the same grade in the same school with a BMI value below the cut-off points for overweight, based on the same charts. All students detected as being overweight in a descriptive study were taken as cases. The two students placed on either side of each case in the attendance register and fulfilling the eligibility criteria were selected as controls. If the students were overweight, the next immediate student was considered for 
sampling. A detailed sampling technique is published elsewhere (15).

A structured pre-tested self-administered questionnaire completed by the parent or guardian was used to collect data of students on socio-demographic factors, physical activity and food consumption pattern. Physical activity was assessed with two different sets of questions; day-to day physical activity and activity of last week using the Physical Activity Questionnaire (PAQ) for older children, which has been developed by Crocker et al. and validated in several countries (16). Of the day-to-day activities, using private vehicles as the mode of transport to school, spending half an hour or more on television viewing per day, sleeping more than eight hours per day, and spending more than three hours on tuition classes per day were defined as being 'less active'. With regard to sleeping, both day time and night time sleep duration was taken as a whole. PAQ assessed the activity of last week in a five-point Likert scale on the following nine items: activity based on some given activities; activity at physical education classes in school, during free times at home, at school interval, just after school, on last weekend and in the evening; overall activity according to parent's view; and time engaged in overall activities of the week. Overall physical activity was assessed with the total marks which defined 'less activity' with less than three marks and 'more activity' with three or more marks.

Food consumption pattern consisted of the questions assessing coconut consumption, oil consumption, meal taking pattern, television viewing while taking meals. Along with that, a food frequency questionnaire was used to assess the frequency of consuming tempered foods, fried foods, milk, yoghurts, butter, margarine, cheese, sausages, sugar added drinks, fruits and vegetables in the last seven days. Food frequency questionnaire was used as it is the most widely used and the best method to assess the diet in large scale epidemiological studies (17). The questionnaire was sent through students to parents or care givers of cases and controls with a consent form. They were instructed to handover the completed questionnaire to the class teacher. Those questionnaires were collected two days later with the help of class teachers.

Data were analysed using Statistical Package for Social Science (SPSS) version 13. OR and its 95\% confidence intervals (CI) were calculated. Multiple logistic regression analysis was applied for controlling confounding factors. Variables that showed a significance level less than 0.2 were entered into the model and analysed with backward elimination method.

\section{Results}

A total of 150 cases and 300 controls were selected. The non-response rate was $24.7 \%(n=111)$. Nonresponse rate of cases was $(n=40,26.7 \%)$ more than that of controls ( $n=71,23.7 \%)$.

In bivariate analysis, mother being employed showed a significant risk for overweight. All other variables in relation to socio-demographic factors were not statistically significant for overweight (Table 1).

The unadjusted ORs calculated for overall activity (assessed using the PAQ) and day-to-day physical activity are shown in Tables 2 and 3, respectively. Engaged in less physical activity at free times, less physical activity during weekends, less overall physical activities and sleeping more than 8 hours per day showed statistically significant associations with overweight in bivariate analysis. Sleeping during day time was not significantly associated with overweight (OR=0.5; $95 \% \mathrm{CI}=0.24$, $1.05 ; \mathrm{p}=0.06$ ).

Factors in relation to food consumption pattern were not significantly associated with overweight. Though not significant, frequent consumption of fruits $(\mathrm{OR}=0.61 ; 95 \% \mathrm{CI}=0.28,1.35 ; \mathrm{p}=0.35)$ and frequent consumption of vegetables $(\mathrm{OR}=0.56$; $95 \% \mathrm{CI}=0.17$, $1.89 ; \mathrm{p}=0.22$ ) were negatively associated with overweight.

After adjusting for confounding effects, less physical activity during weekends was a significant risk factor for overweight. In contrast, sleeping more than 8 hours per day was a significant protective factor (Table 4).

\section{Discussion}

Less physical activity assessed by activities carried out on weekends was a significant risk factor for overweight ( $p=0.008)$. Sleeping more than 8 hours per day was a significant protective factor $(\mathrm{p}=0.001)$. In addition, mother being employed, less physical activity during free time at home, and less physical activity based on overall activities showed statistically significant associations with overweight in univariate analysis. 
Table 1. Unadjusted odds ratios for overweight in relation to socio-demographic factors

\begin{tabular}{|c|c|c|c|c|}
\hline Socio-demographic factors & $\begin{array}{c}\text { Cases } \\
(n=110) \\
\text { No. }(\%)\end{array}$ & $\begin{array}{c}\text { Controls } \\
(n=229) \\
\text { No. }(\%)\end{array}$ & $\begin{array}{c}\text { Odds Ratio } \\
(95 \% \text { CI) }\end{array}$ & $\begin{array}{c}\mathbf{p} \\
\text { value }\end{array}$ \\
\hline Sex: Female & $65(59.1)$ & $141(61.6)$ & $0.9(0.57-1.43)$ & 0.66 \\
\hline Male & $45(40.9)$ & $88(38.4)$ & Ref & \\
\hline Residence: Urban & $30(27.3)$ & $70(30.6)$ & $0.85(0.51-1.41)$ & 0.53 \\
\hline Rural & $80(72.7)$ & $159(69.4)$ & Ref & \\
\hline Care giver: Non parental & $26(23.6)$ & $46(20.1)$ & $0.81(0.31-2.13)$ & 0.67 \\
\hline Parents & $84(76.4)$ & $183(79.9)$ & Ref & \\
\hline Living: With both parents & $103(93.6)$ & $217(94.8)$ & $1.23(0.71-2.12)$ & 0.45 \\
\hline With one or no parent & $7(6.4)$ & $12(5.2)$ & Ref & \\
\hline Father’s employment: Employed & $101(91.8)$ & $213(93.0)$ & $0.84(0.36-1.97)$ & 0.69 \\
\hline Unemployed & $9(8.2)$ & $16(7.0)$ & Ref & \\
\hline Mother’s employment: Employed & $49(44.5)$ & $74(32.3)$ & $1.68(1.05-2.68)$ & 0.03 \\
\hline Unemployed & $61(55.5)$ & $155(67.7)$ & Ref & \\
\hline Father's education: Up to O/ Level & $35(31.8)$ & $67(29.3)$ & $0.6(0.36-1.02)$ & 0.06 \\
\hline Above O/Level & $75(68.2)$ & $162(70.7)$ & Ref & \\
\hline Mother’s education: Up to O/ Level & $25(22.7)$ & $75(32.8)$ & $1.13(0.69-1.85)$ & 0.63 \\
\hline Above O/Level & $85(77.3)$ & $154(67.2)$ & Ref & \\
\hline Monthly income (Rs.): >=20,000 & $64(61.5)$ & $115(53.2)$ & $1.41(0.87-2.26)$ & 0.16 \\
\hline$<20,000$ & $40(38.5)$ & $101(46.8)$ & Ref & \\
\hline Siblings: One or more & $87(79.1)$ & 199 (86.9) & $0.57(0.31-1.04)$ & 0.06 \\
\hline None & $23(20.9)$ & $30(13.1)$ & Ref & \\
\hline Smoking status of father: Yes & $17(15.5)$ & $34(14.8)$ & $1.05(0.56-1.97)$ & 0.88 \\
\hline No & $93(84.5)$ & $195(85.2)$ & Ref & \\
\hline Smoking inside home: Yes & $12(10.9)$ & $16(7.0)$ & $1.63(0.74-3.58)$ & 0.22 \\
\hline No & $98(89.1)$ & $213(93.0)$ & Ref & \\
\hline School type: Non-governmental & $38(34.5)$ & $73(31.9)$ & $1.13(0.70-1.83)$ & 0.62 \\
\hline Others & $72(65.5)$ & $156(68.1)$ & Ref & \\
\hline
\end{tabular}


Table 2. Unadjusted odds ratios for overweight in relation to physical activity assessed by a physical activity questionnaire

\begin{tabular}{|c|c|c|c|c|}
\hline Physical activity & $\begin{array}{c}\text { Cases } \\
(\mathrm{n}=110) \\
\text { No. }(\%) \\
\end{array}$ & $\begin{array}{c}\text { Controls } \\
(n=229) \\
\text { No. }(\%) \\
\end{array}$ & $\begin{array}{l}\text { Odds Ratio } \\
\text { (95\% CI) }\end{array}$ & $\begin{array}{c}\mathbf{p} \\
\text { value }\end{array}$ \\
\hline \multicolumn{5}{|l|}{ Some given activities } \\
\hline : Less active & $103(93.6)$ & 199 (86.9) & $2.2(0.94-5.22)$ & 0.06 \\
\hline : More active ${ }^{1}$ & $7(6.4)$ & $30(13.1)$ & Ref & \\
\hline \multicolumn{5}{|c|}{ Activity pattern in physical education classes } \\
\hline : Less active & 59 (53.6) & $134(54.5)$ & $0.82(0.12-1.3)$ & 0.4 \\
\hline : More active & $51(46.4)$ & 95 (41.5) & Ref & \\
\hline \multicolumn{5}{|c|}{ Activities done at free time in home } \\
\hline : Less active & $94(85.5 \%)$ & $174(76.0)$ & $1.86(1.01-3.42)$ & $<0.01$ \\
\hline : More active & $16(14.5)$ & $55(24.0)$ & Ref & \\
\hline \multicolumn{5}{|c|}{ Activities at school interval } \\
\hline : Less active & $43(39.1)$ & $73(31.9)$ & $1.37(0.85-2.2)$ & 0.19 \\
\hline : More active & $67(60.9)$ & $156(68.1)$ & Ref & \\
\hline \multicolumn{5}{|c|}{ Activities done just after return home } \\
\hline : Less active & $83(75.5)$ & $155(67.7)$ & $1.47(0.88-2.4)$ & 0.14 \\
\hline : More active & $27(24.5)$ & $74(32.30$ & Ref & \\
\hline \multicolumn{5}{|c|}{ Activities done in the evening } \\
\hline : Less active & $75(68.2)$ & $140(61.1)$ & $1.36(0.84-2.2)$ & 0.21 \\
\hline : More active & 35 (31.8) & 89 (38.9) & Ref & \\
\hline \multicolumn{5}{|c|}{ Activities done at weekends } \\
\hline : Less active & $90(81.8)$ & 157 (68.6) & $2.06(1.18-3.61)$ & 0.01 \\
\hline : More active & $20(18.2)$ & $72(31.4)$ & Ref & \\
\hline \multicolumn{5}{|c|}{ Overall activities as parent's view } \\
\hline : Less active & $84(76.4)$ & $155(67.7)$ & $1.54(0.92-2.6)$ & 0.1 \\
\hline : More active & $26(23.6)$ & $74(32.3)$ & Ref & \\
\hline \multicolumn{5}{|c|}{$\begin{array}{l}\text { Time engaged in overall activities in } \\
\text { the week }\end{array}$} \\
\hline : Less active & $76(69.1)$ & $138(60.3)$ & $1.47(0.91-2.4)$ & 0.12 \\
\hline : More active & $34(30.9)$ & $91(39.7)$ & Ref & \\
\hline \multicolumn{5}{|c|}{ Overall physical activity } \\
\hline : Less active & $79(71.8)$ & $35(59.0)$ & $1.77(1.08-2.90)$ & 0.02 \\
\hline : More active & $31(28.2)$ & $94(41.0)$ & Ref & \\
\hline
\end{tabular}

\footnotetext{
${ }^{1}$ Some given activities were bicycling, running, dancing, football, badminton, volleyball, cricket and netball. Activity assessed by the number of days engaged in those activities.
} 
Table 3. Unadjusted odds ratios for overweight in relation to day-to-day activities

\begin{tabular}{|c|c|c|c|c|}
\hline Day-to-day activities & $\begin{array}{c}\text { Cases } \\
(n=110) \\
\text { No. }(\%)\end{array}$ & $\begin{array}{c}\text { Controls } \\
(n=229) \\
\text { No. }(\%)\end{array}$ & $\begin{array}{l}\text { Odds Ratio } \\
\text { (95\% CI) }\end{array}$ & $\begin{array}{c}\mathbf{p} \\
\text { value }\end{array}$ \\
\hline \multicolumn{5}{|l|}{ Mode of transport to school } \\
\hline : Private vehicle & $86(78.2)$ & $172(75.1)$ & $1.19(0.69-2.04)$ & 0.54 \\
\hline : Public transport or walking & $24(21.8)$ & 57 (24.9) & Ref & \\
\hline \multicolumn{5}{|l|}{ Time spent on television } \\
\hline :>=half an hour per day & 89 (80.9) & $171(74.7)$ & $1.44(0.82-2.52)$ & 0.2 \\
\hline$:<$ half an hour per day & $21(19.1)$ & 58 (25.3) & Ref & \\
\hline \multicolumn{5}{|l|}{ Having a computer at home } \\
\hline :Yes & 37 (33.6) & $66(28.8)$ & $1.25(0.77-2.04)$ & 0.37 \\
\hline : No & $73(66.4)$ & $163(71.2)$ & Ref & \\
\hline \multicolumn{5}{|l|}{ Time spent on computer } \\
\hline : >=half an hour per day & $7(6.4)$ & $18(7.9)$ & $0.8(0.33-1.99)$ & 0.64 \\
\hline$:<$ half an hour per day & 102 (93.6) & $211(92.1)$ & Ref & \\
\hline \multicolumn{5}{|l|}{ Time spent on sleeping } \\
\hline$:>=8$ hours per day & 45 (40.9) & 137 (59.8) & $0.46(0.29-0.74)$ & 0.01 \\
\hline$:<8$ hours per day & 65 (59.1) & $92(40.2)$ & Ref & \\
\hline \multicolumn{5}{|l|}{ Sleeping during day time } \\
\hline :Yes & $10(9.1)$ & 38 (16.6) & $0.50(0.24-1.05)$ & 0.06 \\
\hline : No & 100 (90.9) & $191(83.4)$ & Ref & \\
\hline \multicolumn{5}{|l|}{ Attending tuition classes } \\
\hline :Yes & $88(80.0)$ & $184(80.3)$ & $0.98(0.55-1.73)$ & 0.94 \\
\hline : No & $22(20.0)$ & 45 (19.7) & Ref & \\
\hline \multicolumn{5}{|l|}{ Time spent in tuition classes } \\
\hline$:>=3$ hours per day & $52(47.3)$ & $92(40.2)$ & $1.34(0.84-2.11)$ & 0.22 \\
\hline$:<3$ hours per day & $58(52.7)$ & $137(59.8)$ & Ref & \\
\hline
\end{tabular}

Table 4. Adjusted odds ratios for overweight

\begin{tabular}{lcccr}
\hline Cases & $\boldsymbol{\beta}$ & $\begin{array}{c}\text { Standard } \\
\text { error } \\
\text { No. (\%) }\end{array}$ & $\begin{array}{c}\text { Odds Ratio } \\
\mathbf{( 9 5 \% ~ C I ) ~}\end{array}$ & $\begin{array}{c}\mathbf{p} \\
\text { value }\end{array}$ \\
\hline Mother's employment & 0.46 & 0.25 & $1.58(0.98-2.57)$ & 0.06 \\
Sleeping more than 8 hours per day & 0.77 & 0.24 & $0.46(0.29-0.74)$ & $\mathbf{0 . 0 0 1}$ \\
Less physical activity during weekends & 0.77 & 0.29 & $2.17(1.22-3.84)$ & $\mathbf{0 . 0 0 8}$ \\
\hline
\end{tabular}


Less physical activity assessed by activities done during weekends was a risk factor for overweight. Results were consistent with the results of another study done by Veugelers and Fitzgerald, which had shown that more physical activities decrease the risk of overweight (5). However, a statistically significant relationship with physical activity and overweight was not detected by two other Sri Lankan studies $(3,8)$. The difference of results may be due to the different methods of assessing physical activity or differences in study populations. Many cross sectional data had revealed inverse relationship between BMI and physical activity (18-20). However, such correlations did not demonstrate cause and effect relationship. It was difficult to be certain whether overweight individuals were less active because of their obesity or whether a low level of activity caused the obesity.

Sleeping more than 8 hours per day had decreased the risk of overweight. There was no statistically significant association between sleeping in day time and overweight. The results were consistent with global studies $(9,11)$. Short sleeping hours was a risk factor for overweight as revealed by Huil et al. in their case control study in Hong Kong with children aged 6 to 7 years (9). By logistic regression analysis, a doseresponse effect between sleeping duration and overweight was shown. Nine hours per day was taken as reference there. Odds ratio for 9 to 11 hours was 0.54 ( $95 \% \mathrm{CI}=0.3,0.97)$ and OR for more than 11 hours was $0.31(95 \% \mathrm{CI}=0.11,0.87)$. It has been suggested that this relationship may be the result of hormonal mechanism, such as reduction in growth hormone secretion and increase in serum cortisol concentration. The same association was seen in a study carried out in Korean children (11). A longitudinal study done among New Zealand children showed that those who do not get enough sleep are at increased risk of becoming overweight. The weight gain has been described as a result of increased fat deposition rather than additional accumulation of fat free mass (12). A critical review conducted to detect the association between sleep duration and obesity in community has shown a clear pattern that shorter sleep durations were associated with obesity in paediatric population (13). It is not possible to determine whether overweight causes lack of sleep or whether short sleeping duration results in weight gain. Laboratory research and further epidemiological studies specially randomized controlled trials are needed to better understand this association.
A significant association was detected in the univariate analysis $(\mathrm{p}=0.03$ ) between mother being employed and child's overweight, which may be due to other confounding factors. A significant association between using fruits or vegetables with overweight was not detected in the present study. High fibre diets such as vegetables and fruits limit energy intake and reduce the weight gain (1). High intake of dietary fibre promotes weight loss (21). One study had shown that there was a negative association with fruit consumption and adolescent's overweight among Grade 8 students (8). A lower fruit-eating frequency was revealed as a risk factor for children's overweight by a study carried out in Korean children (11). Failure to detect a significant association in the present study may be due to the errors in reporting food frequency leading to bias. Ideally, food frequency questionnaire should be complemented with portion size assessment. Dietary records with portion sizes would give more valid information than food frequency questionnaire. Assessment of frequency of food items consumption over one week may not be adequate to assess dietary patterns.

\section{Conclusions and Recommendations}

Less physical activity during weekends and overall less physical activity were identified as risk factors for overweight. Sleeping more than eight hours per day was a protective factor for overweight. Though not statistically significant, overweight showed a positive association with fatty food and a negative association with high fibre diet.

Parents, teachers and students should be educated regarding the fact that low physical activity is a risk factor for overweight. School curriculum should be revised giving more weightage to physical activity rather than having just a physical education period. Participating at least one physically active sport can be made compulsory for each and every student. Compulsory physical education classes should be implemented in schools. Adequate sleeping, at least eight hours per day, should be encouraged via parents and teachers. Fatty food consumption should be discouraged while high fibre diet consumption should be encouraged with public health policies. It is necessary to educate parents, teachers and students regarding overweight and its consequences. 


\section{Public health implications}

The risk of getting overweight when performing less physical activity and having less sleeping hours should be taken into consideration when planning programmes to reduce childhood overweight. More opportunities should be available for children to have plenty of physical activities and adequate sleep in order to live as healthy adults in future. Parents, teachers as well as children have the responsibility to lessen overweight.

\section{Author Declarations}

Competing interests: The authors declare that they have no competing interests.

Ethics approval and consent to participate: Ethics clearance was granted by Ethics Review Committee of the Faculty of Medicine, University of Kelaniya. Written authorization was obtained from the Zonal Education Director of the Gampaha educational zone. Informed, written consent was taken from parents of selected students.

Funding: We acknowledge the financial assistance granted by the Ministry of Health, Sri Lanka for conducting this research.

Acknowledgements: We are grateful to our study participants, relevant officers in the educational sector and the health sector in Gampaha MOH area.

Author contributions: UP was the principal investigator of the study. UP and CA were involved in the conception and design, acquisition of data, analysis and interpretation of data. UP was involved in drafting the manuscript. UP and CA revised it critically for important intellectual content, and gave final approval of the version.

\section{References}

1. WHO. Obesity: preventing and managing the global epidemic: report of a WHO consultation on obesity technical report series, No.894. Geneva: World Health Organization, 2000.

2. International Life Sciences Institute. Overweight and obesity in European children and adolescent: causes and consequences - prevention and treatment. Europe Overweight and Obesity in Children Task Force, 2000.

3. Wickramasinghe VP, Lamabadusuriya SP, Atapattu N, Sathyadas G, Kuruparananthan S, Karunarathne P. Dietary and physical activity patterns of school children in an urban area of Sri Lanka. Sri Lanka Journal of Child Health 2005; 34: 44-49.

4. Troiano RP, Flegal KM. Overweight Children and Adolescents: Description, Epidemiology, and Demographics. Pediatrics 1998; 101(3): 497-504.

5. Veugelers PJ, Fitzgerald AL. Prevalence of and risk factors for childhood overweight and obesity. Canadian Medical Association Journal 2005; 173(6): 607-613.

6. Stettler N, Bovet P, Shamlaye H, Zemel BS, Stallings VA, Paccaud F. Prevalence and risk factors for overweight and obesity in children from Seychelles, a country in rapid transition: the importance of early growth. International Journal of Obesity 2002; 26(2): 214-219.

7. Toschke AM, Beyerlein A, Kries R. Children at high risk for overweight: a classification and regression analysis approach. Obesity Research 2000; 13: 1270-1274.

8. Sudasinghe SPBH. Prevalence and some associated factors of overweight in year eight school girls in girl's only schools in Gampaha Municipal Council area. MSc Dissertation (Community Medicine). Colombo: Post Graduate Institute of Medicine, University of Colombo, 2006.

9. Hui1 LL, Nelson EAS, Yu LM, Li1 AM, Fok1 TF. Risk factors for childhood overweight in 6- to 7-y-old Hong Kong children. International Journal of Obesity 2003; 27: 14111418.

10. Lajunen HR, Rahkonen AK, Pulkkinen L, Rose RJ, Rissanen A, Kaprio J. Are computer and cell phone use associated with body mass index and overweight? a population based study among twin adolescents. BMC Public Health 2007; 7: 24.

11. Kang HT, Ju YS, Park KH, Kwon YJ, Im HJ, Paek DM, Lee HJ. Study on the relationship between childhood obesity and various determinants, including socioeconomic factors, in an urban area. Journal of Preventive Medicine and Public Health 2006; 39(5): 371-8.

12. Carter PJ, Tayler BJ, Williams SM, Taylor RW. Longitudinal analysis of sleep in relation to BMI and body fat in children: the FLAME study. British Medical Journal 2011; 342: d2712. 
13. Marshall NS, Glozier N, Grunstein RR. Is sleep duration related to obesity? A critical review of the epidemiological evidence. Sleep Medicine Reviews 2008; 12(4): 289-98.

14. Cole TJ, Bellizzi MC, Flegal KM. Establishing a standard definition for child overweight and obesity worldwide: international survey. British Medical Journal 2000; 320: 1240-1243.

15. Perera U, Abeysena C. Prevalence of overweight and obesity in grade five students in schools of Gampaha Medical Officer of Health area. Journal of the College of Community Physicians of Sri Lanka 2014; 19(2): 11-16.

16. Physical Activity Questionnaire for Older Children and Adolescents' Manual (Online). Available from: http:// rds.yahoo.com/s=96062901/k=questionnaire+to+assess +physical+activity+of+adolescents/v=2/SID=e/1=cp/SIG= 12csns301/Exp=117 [Accessed on 23.04.20.
17. Shim J, Oh K, Kim HC. Dietary assessment methods in epidemiologic studies. Epidemiology and Health 2014. Available online http://dx.doi.org/10.4178/epih/e2014009.

18. Schulz LO, Schoeller DA. Acompilation of total daily energy expenditures and body weights in healthy adults. American Journal of Clinical Nutrition 1994; 60: 676-681.

19. Davies PS, Gregory J, White A. Physical activity and body fatness in preschool children. International Journal of Obesity and Related Metabolic Disorders 1995; 19: 6-10.

20. Westerterp KR, Goran Ml. Relationship between physical activity related energy expenditure and body composition: a gender difference. International Journal of Obesity and Related Metabolic Disorders 1997; 21: 184-188.

21. Pereira MA, Ludwig DS. Dietary fiber and body weight regulation: observations and mechanisms. Pediatric Clinics of North America 2001; 48: 969-980. 